\title{
Clopidogrel and Surgical Intervention: A point to ponder
}

\author{
Chandrasinghe P.C,MBBS ${ }^{1}$, Liyanage C.A.H,MBBS, MS, M.Phil, MRCS ${ }^{2}$ \\ 1 Registrar, University Surgical Unit, North Colombo Teaching Hospital, Ragama, Sri Lanka. \\ 2 Consultant Surgeon, University Surgical Unit, North Colombo Teaching Hospital, Ragama, Sri Lanka.
}

Key words: Clopidogrel; Surgery; Risk of haemorrhage.

\section{Introduction}

Clopidogrel is an antiplatelet agent with an irreversible effect on platelet function. It is being used commonly in patients with ischaemic heart disease and occlusive vascular disease. The anti aggregating property of clopidogrel is caused by an inhibition of the binding of ADP to its platelet receptors $\left(\mathrm{P} 2 \mathrm{Y}_{12}\right)$. The effectiveness of the drug is dependent on its activation to an active metabolite by the cytochrome P450 (CYP) system, principally CYP2C19.

We have experienced a number of life threatening events of post operative bleeding associated with antithrombotic therapy with clopidogrel in the recent past. Most of these patients were on the drug for over a year prior to surgery, for ischaemic heart disease. All these patients had withheld the drug for over two weeks pre-operatively. This led us to search for literature on its' effects on surgery and recommendations for the use of clopidogrel. Liyanage et al [1], in a questionnaire based study, amongst surgeons, reported 65 events of haemorrhage with $6(9.23 \%)$ mortalities within a year.

\section{Clopidogrel and Coronary Artery Bypass Graft (CABG)}

Many studies on the effect of clopidogrel in CABG could be found with conflicting evidence

Correspondence: C.A.H. Liyanage, Consultant Surgeon,

University Surgical Unit, North Colombo Teaching Hospital,

Ragama, Sri Lanka.

Email: chandikaliyanage $(a$ hotmail.com

The Sri Lanka Journal of Surgery 2011; 29(1):10-14.
$[2,3,4]$. The American Heart Association (AHA) guidelines recommend withholding the drug for five days prior to CABG [5]. Kim and colleagues concluded that use of clopidogrel within 5 days prior to surgery was not significantly associated with the primary outcome measure of reoperation for CABG-related bleeding [2]. Chu et al found that clopidogrel that is given within four days of coronary bypass surgery was associated with an increase in blood loss, reoperation for bleeding and transfusion requirement [3] while Pickard and colleagues had similar experience with clopidogrel exposure within seven days of CABG [4].

\section{Clopidogrel and general surgery}

Evidence regarding the effect of clopidogrel in general surgical procedures is scarce and there are no guidelines about when to withhold the drug pre-operatively [6]. In a recent study, Chu et al concluded that use of clopidogrel within 7 days of inguinal herniorrhaphy did not increase the risk of perioperative bleeding complications [7]. However, their study included only 46 patients which largely questions its' power. Furthermore, a minor procedure such as hernia repair will not project the magnitude of the risk of bleeding with major procedures like intra abdominal operations, neck dissections and mastectomy, where large areas of raw cut surface leave potential for oozing and blood loss. Liyanage et al [1] have reported $23(35 \%)$ events of haemorrhage related to general surgical procedures. We could not find a single randomised trial which addresses the impact of clopidogrel use in major procedures such as in abdominal operations. 


\section{Clopidogrel and intracranial haemorrhage}

In 2005, Cay [9] reported the first case of spontaneous intracranial haemorrhage in a patient using clopidogrel. Cordina et al, in a retrospective analysis, concluded that mortality with clopidogrel related intra-cranial haemorrhage appears to be higher than that observed with aspirin [8]. Wong et al, who studied the outcome after traumatic brain injury in one hundred and thirty one elderly patients, concluded that patients on clopidogrel were more likely to die $(\mathrm{OR}=$ 14.7; 95\% CI: 2.3-93.6) and were likely to be discharged to an inpatient long-term facility (OR $=3.25 ; 95 \%$ CI: 1.06-9.96) [10]. In the Clopidogrel for High Athero thrombotic Risk and Ischemic Stabilization, Management and Avoidance (CHARISMA) [14] trial, analysis of safety endpoints showed similar rates of primary intracranial haemorrhage between aspirin monotherapy and aspirin combined with clopidogrel $(0.3 \%$ versus $0.3 \%$ : $\mathrm{P}=0.89)$ amidst a significantly higher incidence of moderate (GUSTO classification) haemorrhage elsewhere.

\section{Indications for the use of clopidogrel}

Clopidogrel is not recommended by both the National Health Services (NHS) of the United Kingdom and the American Heart Association (AHA) for primary prevention of ischaemic heart disease or vascular events [5,11]. It is only recommended for use in secondary prophylaxis following such events for a maximum of one year. The only indication for clopidogrel to be used for a period of over one year is hypersensitivity to aspirin or intolerable dyspeptic symptoms with aspirin. The indications and the recommended time periods for the use of clopidogrel according to the NHS and AHA are shown in table 1.

\section{Benefit of clopidogrel use}

\section{Adding clopidogrel to aspirin after acute coronary syndrome (ACS)}

The effects of clopidogrel in addition to aspirin in patients with ACS without ST segment elevation, the CURE study incorporating 12,562 patients,
Table 1: Recommended duration of use for clopidogrel: National Health Services (2009) and American Heart Association (2007) guidelines.

\begin{tabular}{|c|c|}
\hline Event & Recommendation \\
\hline $\begin{array}{l}\text { Non ST elevation } \mathrm{MI} \\
\text { (NSTEMI) }\end{array}$ & $\begin{array}{l}75 \text { mg daily for } 12 \text { months } \\
\text { with aspirin* }\end{array}$ \\
\hline ST elevation MI & $\begin{array}{l}75 \mathrm{mg} \text { daily for at least } 4 \\
\text { weeks and not more than } \\
12 \text { months with aspirin* }\end{array}$ \\
\hline $\begin{array}{l}\text { Percutaneous Coronary } \\
\text { Interventions (PCI) } \\
\text { 1.Stent insertion }\end{array}$ & \\
\hline - Bare metal stents & $\begin{array}{l}75 \mathrm{mg} \text { daily for } 4 \text { weeks } \\
\text { with aspirin* }\end{array}$ \\
\hline - Drug eluting stents & $\begin{array}{l}75 \text { mg daily for } 12 \text { months } \\
\text { with aspirin* }\end{array}$ \\
\hline 2.Balloon angioplasty & $\begin{array}{l}75 \mathrm{mg} \text { daily for } 4 \text { weeks } \\
\text { with aspirin* }\end{array}$ \\
\hline $\begin{array}{l}\text { Post Coronary Artery } \\
\text { Bypass Graft }\end{array}$ & $\begin{array}{l}75 \mathrm{mg} \text { daily for } 3 \text { months } \\
\text { with aspirin* }\end{array}$ \\
\hline $\begin{array}{l}\text { Secondary prevention of } \\
\text { occlusive vascular event } \\
\text { while on aspirin }\end{array}$ & Not recommended \\
\hline $\begin{array}{l}\text { Primary prevention of } \\
\text { occlusive vascular events }\end{array}$ & Not recommended \\
\hline
\end{tabular}

* Aspirin to be continued thereafter indefinitely

compared the combination of clopidogrel with aspirin to aspirin given alone in patients admitted with ACS [12]. It was found that addition of clopidogrel reduced the risk of a non-fatal myocardial infarction but that the number needed to treat (NNT) was 48 , i.e. 48 patients had to be treated with clopidogrel plus aspirin, instead of aspirin alone, to prevent one non-fatal myocardial event. Furthermore, little additional benefit over aspirin alone was seen, from continuing such therapy for over three months with an NNT of 500. Also, a significant risk of bleeding was observed in the aspirin plus clopidogrel group (3.7\% versus $2.7 \% ; \mathrm{P}=0.001)$.

\section{Addition of clopidogrel for primary prevention}

The CHARISMA trial compared the effect in addition of clopidogrel to aspirin against aspirin alone in high risk patients [14]. Fifteen thousand six hundred and three patients were randomised. There was no significant difference in the occurrence of either fatal or nonfatal myocardial 
infarctions, fatal or non-fatal stroke from any cause or cardiovascular deaths $(6.8 \%$ for combined therapy vs. $7.3 \%$ for aspirin monotherapy: $\mathrm{P}=0.22$ ). However, addition of clopidogrel was found to be associated with a significant increase in moderate bleeding complications $(2.1 \% \mathrm{Vs} 1.3 \%$ : $\mathrm{P}<0.001)$.

\section{Clopidogrel versus aspirin}

Randomised clinical trials have revealed that clopidogrel alone has no clear benefit over using aspirin alone in secondary prophylaxis. The CAPRIE trial, which looked at clopidogrel versus aspirin in patients at risk of ischaemic events, included 19,000 subjects. This trial showed that the risk of a new ischaemic event (coronary, cerebrovascular or peripheral vascular) with the use of clopidogrel instead of asprin was $5.3 \% \mathrm{Vs}$ $5.8 \%$ [13]. The number needed to be treated was 200 , for one year, to prevent one ischaemic event at an extra cost of $£ 92,000$. Furthermore, the addition of clopidogrel significantly increased the absolute rate of major bleeding (defined as substantially disabling bleeding, intraocular bleeding leading to loss of vision, or bleeding necessitating transfusion of at least 2 units of blood) by $1 \%$. That is, of 100 people treated for about 9 months, one would suffer severe harm associated with the addition of clopidogrel.

\section{Addition of clopidogrel to aspirin after ST segment elevation Myocardial Infarction (STEMI)}

Two studies provide the evidence for the use of clopidogrel in STEMI, in addition to aspirin, with marginal benefits. In the clopidogrel as adjunctive reperfusion therapy (CLARITY) trial [15] [ $\mathrm{n}=3500]$, clopidogrel was given in addition to aspirin until thrombolytic therapy was established or for a maximum of eight days and stopped. There was a $6.7 \%$ absolute risk reduction in the composite endpoint of cardiovascular death and stroke after Percutaneous Coronary Intervention (PCI) or at discharge without intervention compared to placebo.

In the clopidogrel and metoprolol in myocardial infarction trial (COMMIT) [16] [ $\mathrm{n}=45,852]$, clopidogrel was given for up to 4 weeks (mean 15 days)in addition to aspirin which produced only a marginal total risk reduction in all cause mortality (7.5\% in aspirin with clopidogrel Vs $8.1 \%$ in aspirin alone; $\mathrm{P}=0.03$ ).

\section{Addition of clopidogrel after stroke}

The management of atherothombosis with clopidogrel in high-risk patients (MATCH) trial compared clopidogrel monotherapy with clopidogrel plus aspirin in preventing major vascular events in patients with stroke or transient ischaemic attacks [17]. The study included 7599 patients and concluded that there was no benefit in combination treatment to reduce the risk of ischaemic events. However the risk of lifethreatening bleeding increased. The rate of life threatening hemorrhage reported was $2.6 \%$ in combined therapy vs. $1.3 \%$ in mono-therapy with an absolute risk increase of $1.3 \%$ [95\% CI 0.6 to 1.9].

It is evident from existing data that addition of clopidogrel has a marginal benefit after ischaemic cardiac events with a more serious side effect profile compared to aspirin. All of the studies to date and the guidelines from the AHA and NHS recommend only short term (less than a year) use of the drug. In the local setting, we come across many patients taking clopidogrel indefinitely. It has also been postulated that prolonged use of clopidogrel results in coagulation derangement similar to acquired haemophilia [18]. This may explain uncontrolled bleeding we have experienced in some of our patients, even after withholding the drug for two weeks prior to surgery. There are no antidotes to counter bleeding associated with clopidogrel or guidelines on managing such events. Preoperative platelet transfusion, tranexamic acid, Factor VII [19] and aprotinin have all being tried, with no clear benefit in countering the antithrombotic effect of clopidogrel.

It is essential for surgical teams to be aware of this drug, particularly in the emergency room, where we face an ever-increasing burden of road traffic trauma [20]. Worse still, trauma victims may be unaware of their current medication status. To this 
end, a 'medic-alert card' indicating clopidogrel use, will alert emergency room staff to the special risks that patients may face. We believe the time is ripe for unambiguous guidelines regarding the use of clopidogrel in Sri Lanka.

\section{References}

1. Liyanage CAH, Jayaweera KKDG, Deen KI. Clopidogrel and surgery: "Be aware". Sri Lanka Journal of Surgery 2010; 28(1):1-4.

2. Kim JH, Newby K, Clare RM et al. Clopidogrel use and bleeding after coronary artery bypass graft surgery. American Heart Journal 2008; 156:886-892.

3. Chu MW, Wilson SR, Novick RJ, Stitt LW, Quantz MA. Does clopidogrel increase blood loss following coronary artery bypass surgery? Annals of Thoracic Surgery 2004; 78(5):1536-41.

4. Pickard AS, Becker RC, Schumock GT, Frye CB. Clopidogrel-associated bleeding and related complications in patients undergoing coronary artery bypass grafting. Pharmacotherapy. 2008; 28(3): 376-92.

5. Jeffrey LA,Cynthia DA, Elliott MA et al: ACC/AHA 2007 Guidelines for the Management of Patients With Unstable Angina/NonST-Elevation Myocardial Infarction. Journal of American College of Cardiologists 2007; 50:1-157.

6. Ozao-Choy J, Tammaro Y, Fradis M, Weber K, Divino CM. Clopidogrel and bleeding after general surgery procedures. American Journal of Surgery 2008; 74(8): 721-5.

7. Chu EW, Telem DA, Chernoguz A, Divino CM. Assessing the risk of clopidogrelrelated bleeding complications in patients undergoing inguinal herniorrhaphy. Hernia. 2010; 15(1):31-5.

8. Steve M Cordina, Ameer E Hassan, Mustapha A. Ezzeddine. Prevalence and Clinical Characteristics of Intracerebral Hemorrhages Associated with Clopidogrel. Journal of Vascular andInterventional Neurology 2009; 2(1):136-138.

9. Serkan Cay, Mehmet Birhan Yilmaz and Sule Korkmaz.Intracranial Bleeding Associated with Clopidogrel.
Cardiovascular Drugs and Therapy 2005; 19(2):157-158.

10. Wong, DK, Lurie F, Wong LL.The Effects of Clopidogrel on Elderly Traumatic Brain Injured Patients. Journal of Trauma-Injury Infection \& Critical Care: 2008; 65(6):13031308.

11. Derbyshire JAPC Guideline - Guidance of the Use of Clopidogrel PB/MMPB June 2008; Review Date: June 2010.

12. The CURE trial investigators. Effects of Clopidogrel in Addition to Aspirin in Patients with Acute Coronary Syndromes without ST Segment Elevation. New England Journal of Medicine 2001; 345: 494-502.

13. Gent $\mathrm{M}$ et al (CAPRIE steering committee). A randomised, blinded, trial of clopidogrel versus aspirin in patients at risk of ischaemic events (CAPRIE). Lancet 1996; 348:13291339.

14. Bhatt DL, Fox KAA, Hacke $\mathrm{W}$ et al. Clopidogrel and Aspirin versus aspirin alone for the prevention of atherothrombotic events (CHARISMA).New England Journal of Medicine 2006; 354:1706-17.

15. Gibson CM, Ly HQ, Murphy SA et al. Usefulness of clopidogrel in abolishing the increased risk of reinfarction associated with higher platelet counts in patients with ST-elevation myocardial infarction (results from CLARITY-TIMI 28). Am J Cardiol. 2006 Sep 15;98(6):761-3.

16. Chen ZM Pan HC Chen YP et al. Early intravenous then oral metoprolol in 45,852 patients with acute myocardial infarction: randomised placebo-controlled trial.Lancet 2005; 366(9497): 1622-32.

17. Aspirin and clopidogrel compared with clopidogrel alone after recent ischaemic stroke or TIA in high risk patients (MATCH): randomised, double-blind, placebo-controlled trial. Lancet 2004; 364: 331-7.

18. Balamuththusamy S, Arora R. Haematologic adverse effects of clopidogrel. American Journal of Therapeutics 2007; 14:106-12. 
19. Halkos ME, Levy JH, Chen E et al. Early experience with activated recombinant factor VII for intractable hemorrhage after cardiovascular surgery. Annals of Thoracic
Surgery 2005;79:130.

20. Bulletin of the Accident Service of the National Hospital of Sri Lanka 2006. 